\title{
DYNAMIC BEHAVIOR OF FERROCEMENT PLATES
}

\author{
M. A. EL-Sissy - A. A. Hamada Y. B. Shaeen \\ Production Engineering and Mechanical Design Dept., Faculty of Engineering, \\ Minoufiya University, Shebin El-Kom, Egypt
}

\begin{abstract}
Thin ferrocement plates reinforced with various types of expanded steel meshes were developed with high strength, crack resistance, high ductility and energy absorption properties which might be useful for dynamic applications. Five series of plates were casted and tested under four different loading conditions. The dynamic responses such as: frequency, mode shape and damping factor were extensively investigated using FFT analyzer. The experimental analysis and finite element technique were utilized to study the effect of network configurations and boundary fixations on dynamic characteristics.

In addition, the investigated composite plates were tested in the high frequency range (up tol20 $\mathrm{kHz}$ ) through ultrasonic attenuation technique. For this purpose, an experimental setup was designed and constructed to measure dynamic elastic modulus, phase velocity and damping attenuation. The effect of mesh-layer debonding on the dynamic characteristics (natural frequency and damping ratio) was investigated. Damage was detected using vibration measurements and identified by comparing signals in higher frequency ranges before and after damage.

تمثاز ألوأح الفيروسمنت المعززة بأنواع مخثلفة من شبلك الصنب بالمتانة العالية ومتاومتها للشرخ منغ ممطوليه

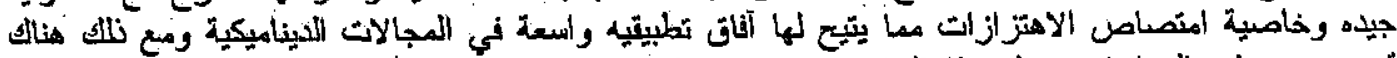

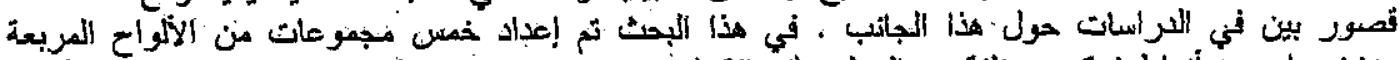

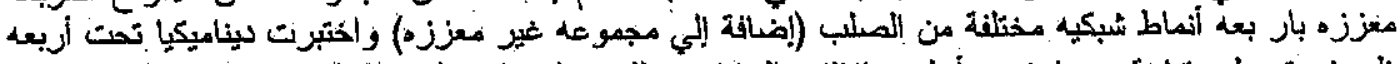

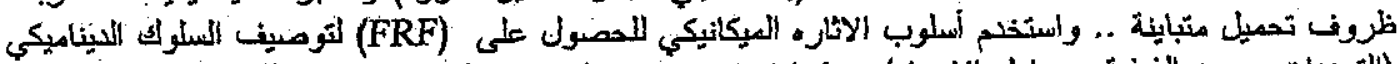

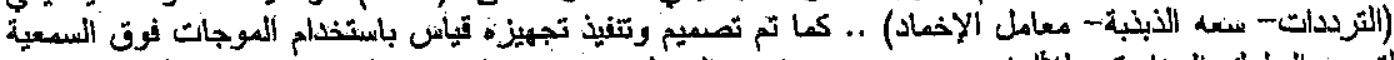

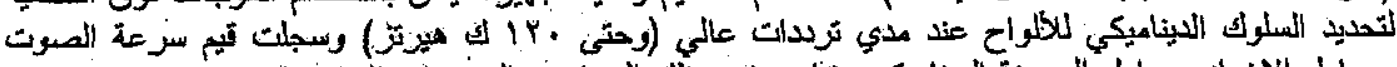

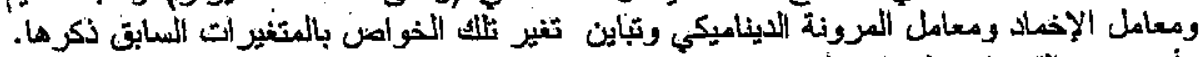

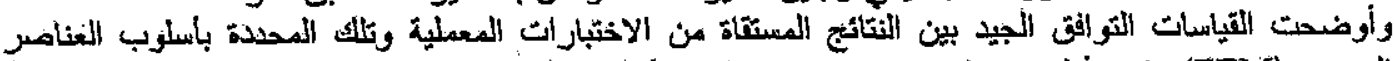

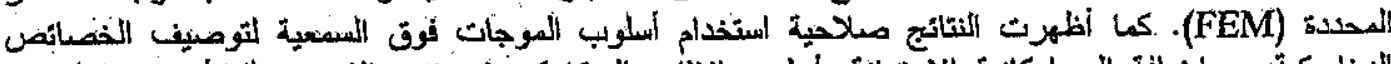

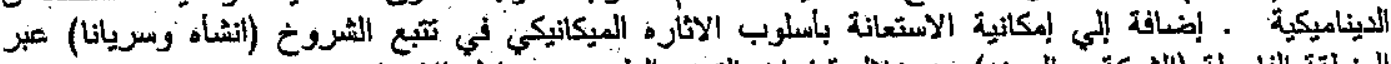

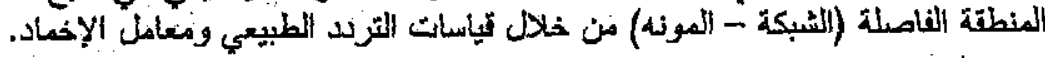

Keywords: Modal Testing - Finite Element - Ferrocement Composite - Ultrasonic Test.

\section{INTRODUCTION}

Ferrocement is a type of thin wall reinforced concrete commonly constructed of hydraulic cement mortar reinforced with closely spaced layers of continuous and relatively small size wire mesh [1]. In its role as a thin reinforced concrete prodiuct and as a laminated cement-based composite, ferrocement has found itself in numerous applications both in new structures and repair and rehabilitation of existing structures. Compared with the conventional reinforced concrete, ferrocement is reinforced in two directions; therefore, it has homogenous-isotopic properties in two directions. Benefiting from its usually high reinforcement ratio, ferrocement generally has a high tensile strength and a high modulus of rupture. In addition, because the specific surface of reinforcement of ferrocement is one to two orders of magnitude higher than that of reinforced concrete, larger bond forces develop with the matrix resulting in average crack spacing arid width more than one order of magnitude smaller than in conventional reinforced concrete [2-3]. Other appealing features of ferrocement include ease of prefabrication and low cost in maintenance and repair. Based on the aforementioned advantages, the typical applications of ferrocement include water tanks, boats, housing wall panel, roof, formwork and sunscreen [4-6].

The renaissance of ferrocement in recent two decades has led to the ACI design guideline "Guide 
for the Design, Construction, and Repair of Ferrocement"[7], and publications such as "Ferrocement Design, Techniques, and Application" [8] and "Ferrocement and Laminated Cementitious Composites"[9], which provide comprehensive understanding and detailed design method of contemporary ferrocement. However, the rapid development in reinforcing meshes and matrix design requires continuous research to characterize the new material and improve the overall performance of ferrocement. Thus far steel meshes have been the primary mesh reinforcement for ferrocement, but recently fiber reinforced plastic (FRP) meshes were introduced in ferrocement as an promising alternative to steel meshes [10-14]. Compared with steel, FRP materials possess some remarkable features such as lightweight, high tensile strength and inherent corrosion resistance. However, unlike steel that has an elastic-plastic stress-strain relationship, FRP materials behave eiastically up to failure, thus do not yield and lack ductility.

Investigation of the dynamic behavior of ferrocement composites plates in the literature is rarely available. However, linited studies were carried out on reinforced concrete structures subjected to dynamic loads (e.g. bridge) to characterize their dynamic behavior for the purpose of fault diagnosis. Here are some examples:

Salawu, W. [15], conducted full-scale forcedvibration tests before and after structural repairs on a multi span reinforced concrete highway bridge. The tests were conducted to study any correlation between repair works and changes in the dynamic characteristics of the bridge. Comparison of the mode shapes before and after repairs using modal analysis procedures was found to give an indication of the repair. The bridge response was measured using accelerometers and the modal parameters were extracted from the frequency response function. The result of this study showed that damping ratio could not be used as an indicator for damage.

Koh and Ray [16], used mode shapes and natural frequencies for model updating method. The finite element model updating process modifies parameters in the global stiffness or mass matrix to reproduce the measured modal data. Thus, local perturbation of parameters in the global stiffness or mass matrix indicates damage location.

Richardson [17], focused on the determination of the functional relationship between variations in the mass, stiffness, damping and the variations in the model properties of the structure. This function could be in a simple form in case of small changes to detect, locate and quantify structural faults by monitoring frequency and damping only. The complete sensitivity function for mass stiffness and damping also the validity of the stiffness sensitivity for small changes were verified using a $3 \mathrm{DOF}$ numerical example [18].

In the present work, modal testing is performed using accelerometers and data acquisition system to measure structure dynamic response. Collected data are used through some signal processing analysis to extract the dynamic parameters. On the other hand, the theoretical models are fine tuned to simulate the existing structure. These tuned fine models are used to form a data base for structure dynamic behavior under different boundary conditions.

This research covers the application of two different techniques, namely, mechanical excitation and ultrasonic to characterize the dynamic behavior of the investigated composite plates made from ferrocement. The scope of research covers the numerical simulation and experimental verification.

\section{MODAL ANALYSIS USING THE FINITE ELEMENT METHOD}

A typical composite ferrocement plates of dimensions $(150 \times 150 \times 10) \mathrm{mm}$ with various boundary conditions, C-F-F-F, C-S-F-F, C-C-F-F and $\mathrm{C}-\mathrm{C}-\mathrm{C}-\mathrm{C}$ along the edges of plate are modeled using the finite element method where $C$ clamped, $S$ simply supported, $\mathrm{F}$ free. The equivalent elastic modulus and density of ferrocement composite are computed also, different open mesh, various volume fraction and boundary conditions are employed. A mesh of $20 \times 20$ elements, eight node brick elements are utilized in the analysis and as shown in Fig. 1.

The stiffness matrix of the element can be then formulated as [19]:

$$
[\mathrm{K}]=\mathrm{t} \iint[\mathrm{B}]^{\mathrm{T}}[\mathrm{D}][\mathrm{B}] \mathrm{dx} d \mathbf{y}
$$

Where, 1 is the thickness of ferrocement plate, $[B]$ is strain matrix and [D]is the elasticity matrix of ferrocement plate, which can be computed according to Ref. [20].

Consequently, the mass matrix of element can be formulated [19] as:

$$
[\mathrm{M}]=\rho \iint[\mathrm{N}]^{\mathrm{T}}[\mathrm{N}] \mathrm{dx} d \mathbf{y} .
$$

Where, $\rho$ is the density of the equivalent composite plate with various mesh type, $[\mathrm{N}]$ is the matrix of shape function. , Ref. [21].

The eigen-frequency can be then evaluated from the solution of the characteristic equation for composite plate given by:

$$
|[K]-\lambda[M]|[V]=[0]
$$

The eigen values and mode shapes are computed uses the F.M soft ware package ANSYS (Version 5.4).

Initially, the plates were modeled in order to get a first estimation of the undamped natural frequencies and mode shapes utilizing finite elements type SOLID65. 


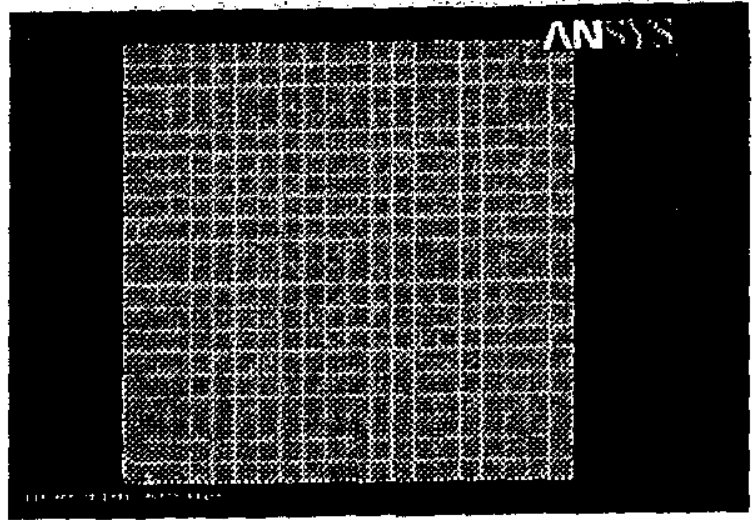

Fig. 1 Finite element model for ferrocement plate were computed for different mesh types and boundary fixations and are listed in Table (1).

\section{EXPERIMENTAL PROCEDURE}

\subsection{Materials Preparation}

The experimental program was designed to investigate the effect of . reinforced steel mesh configurations and boundary conditions on the dynamic behavior of ferrocement plates. Five different patterns of mesh reinforcements were used. Different materials were used to produce the plates $(150 \times 150 \times 10) \mathrm{mm}$ including: mortar, steel meshes, silica fume, super-plasticizer, fly ash and polypropylene fibers. The experimental details were described elsewhere [21].

The material properties were then entered in the program, and the constraint imposed to simulate a type of fixation. The numerical results using FEM

Table (1) Values of the first five frequencies in $\mathrm{Hz}$ for ferrocement plates under four different boundary conditions (Finite element and experimental results).

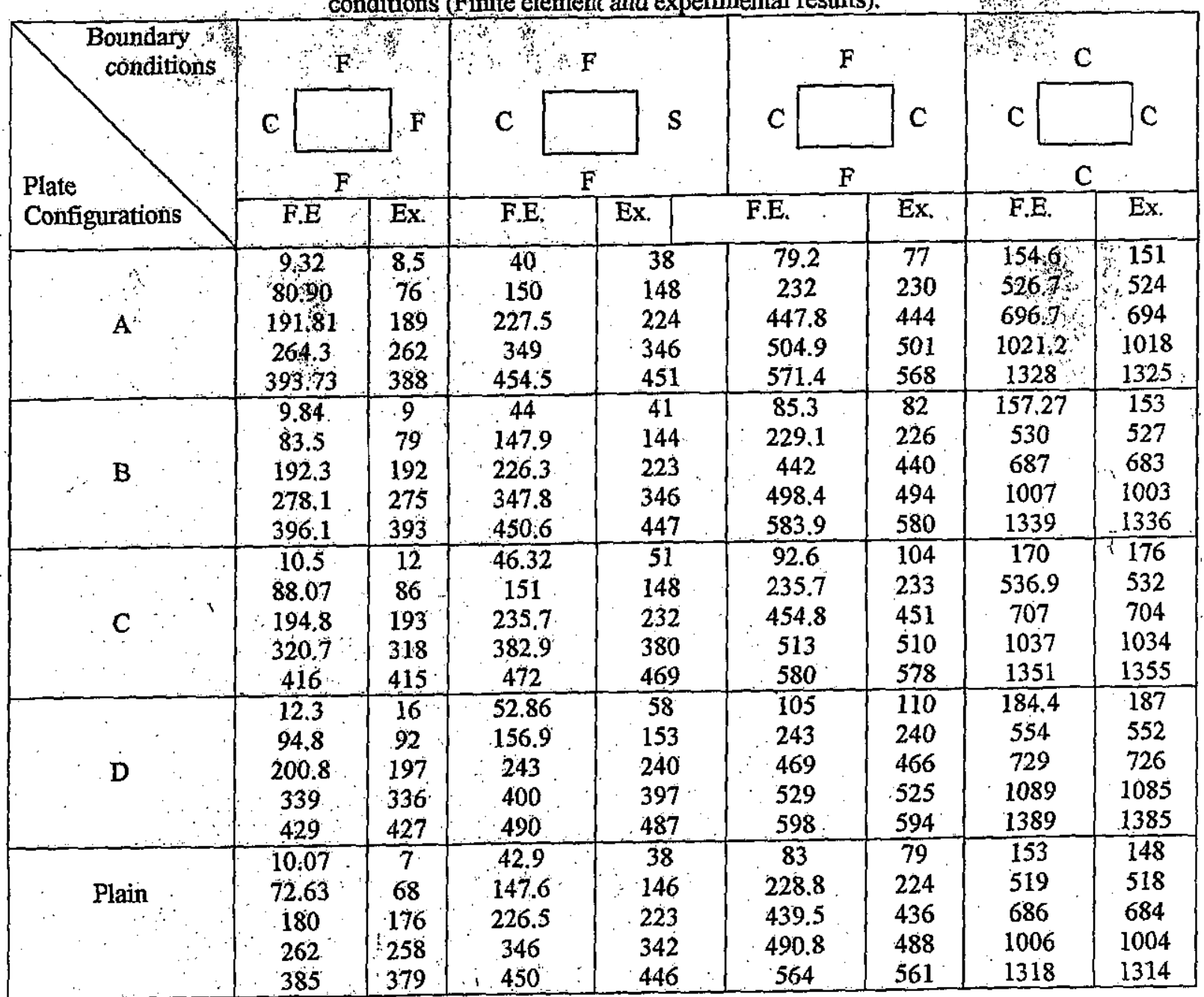

\subsection{Frequency Response Function}

The experimental set up, used in the present work, was described in details before [21] where the : specimen was located in a test rig and excited by an Impact hammer "type 8202", which resembles an ordinary hammer but has a force transducer type 
' 8200 ' built into its tip to register the force input. The hammer was used to excite the specimen at the midpoint position. The charge amplifier type ' 2635 ' was used to generate the signal from the hammer to the dual channel analyzer type '2034'. The vibration response was registered by a suitable piezoelectric accelerometer (type ' 4374 ' its weight ' 2.4 grams'). The vibration meter (type 2511) was utilized in connection with the accelerometer to generate the signal to the dual channel analyzer (type 2034). The frequency response spectrum was recorded and printed. A sample of the recorded responses is shown in Fig. (2).

The frequency and damping factor measurements for the fundamental frequency and associated damping factor were carried out for each specimen. The experimental results were taken as an average of five measurements of each. The damping factor $(\xi)$ of a particular resonance was calculated from the width of the resonance peak in the magnitude of the (FRF) The experimental measurements of frequency, amplitude and damping factor are listed in Table (2).

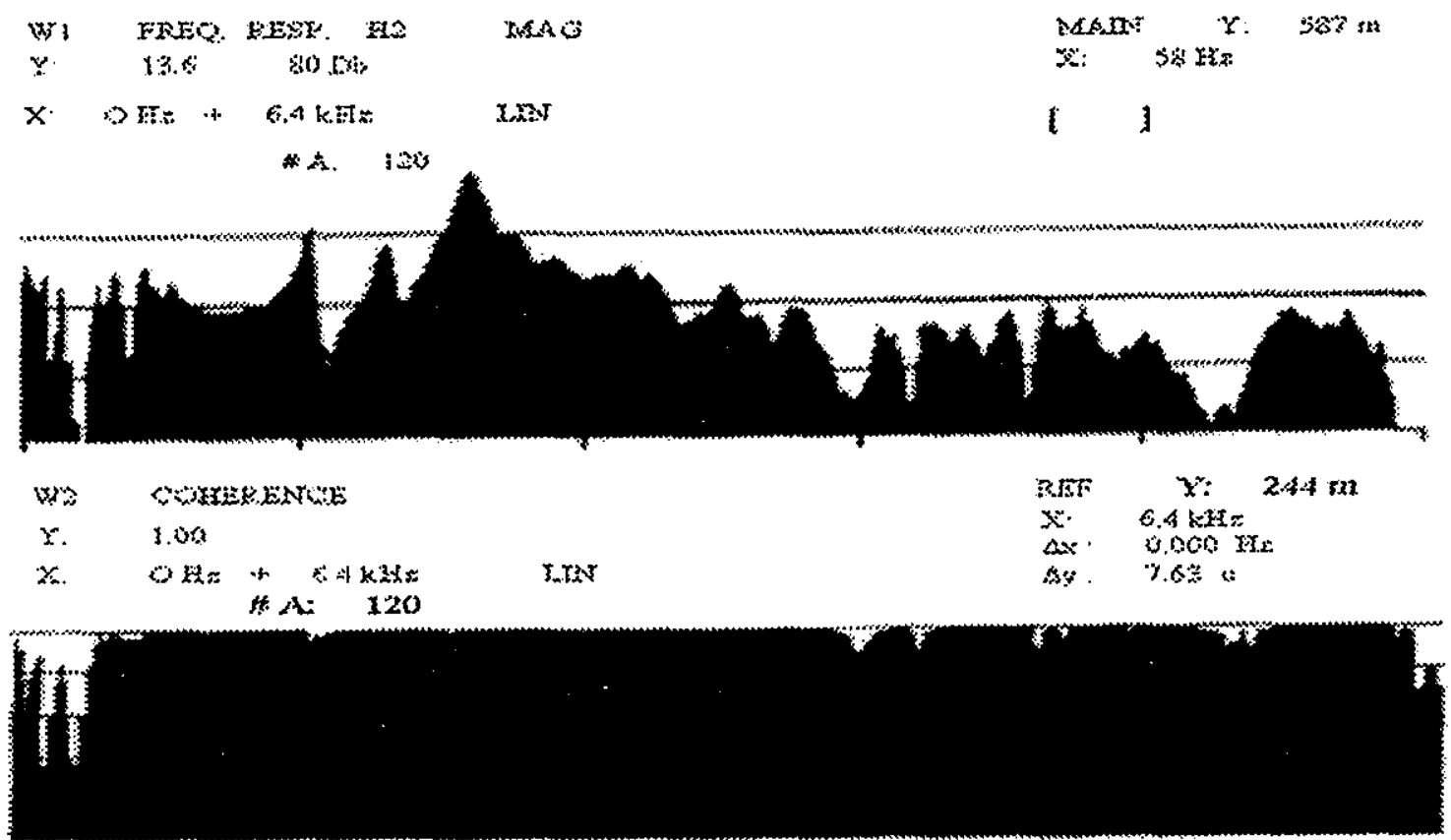

Fig. 2 A sample of frequency response function and coherence function for ferrocement plate (A-type, C-C-F-F)

Table (2) Values of fundamental frequency $(\mathrm{Hz})$, amplitude $(\mathrm{dB})$ and damping factor for ferrocement plates tested under four different boundary conditions* (experimental results).

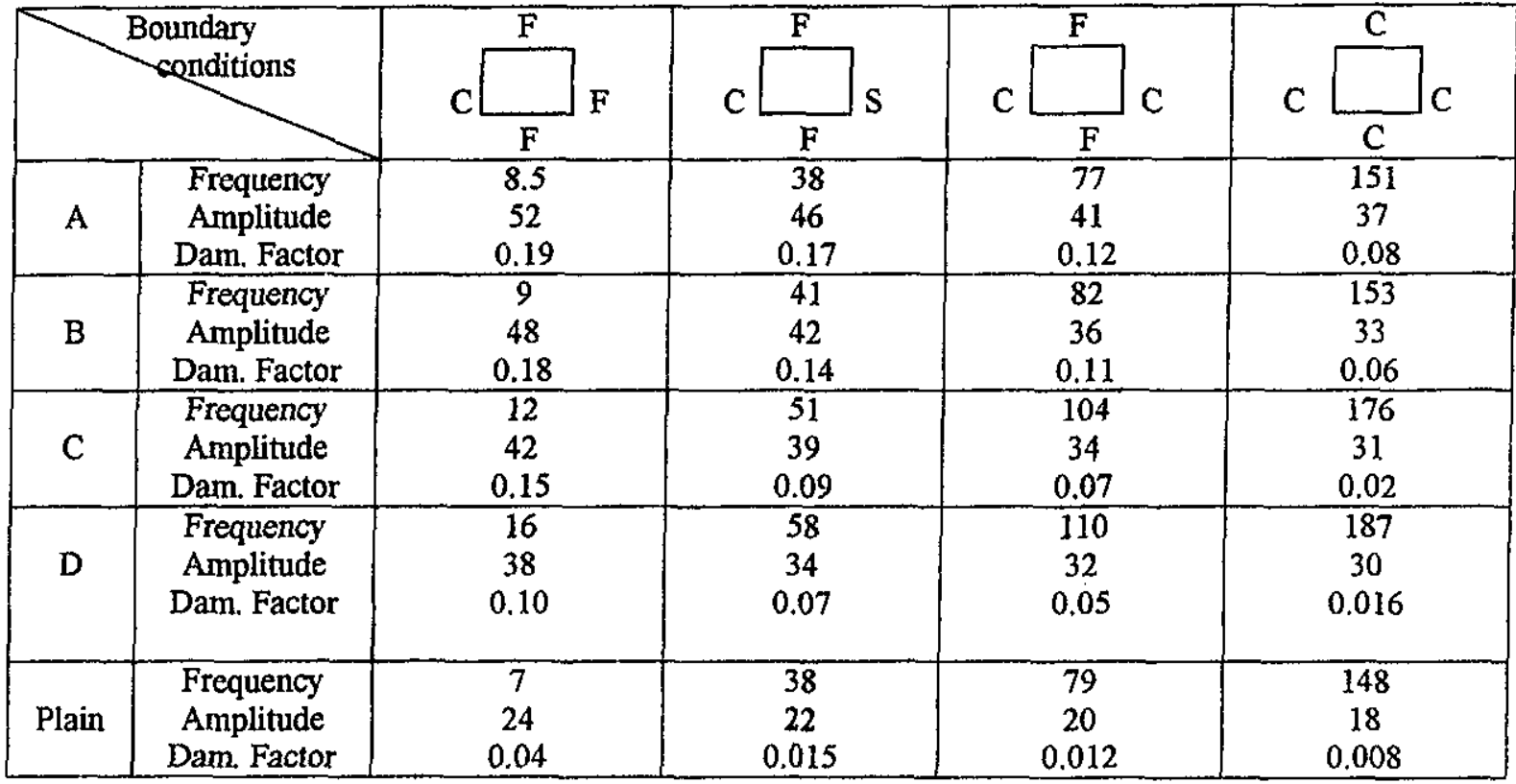




\subsection{Damage Identification Using Structural Dynamic Analysis}

To study the effect of mesh-layer debonding on the vibration characteristics of ferrocement plates, the plates were provided with debonding lengths: 10,20 , $30,40,50 \& 60 \mathrm{~mm}$ by inserting aluminum foils of various sizes on the upper surface of the reinforcing mesh. Figure (3) depicts the configuration of the experimental set-up for vibration testing of cracked plate. The fundamental frequency of cracked plate was recorded and compared with those for noncracked plate. The input parameters were crack length and plate type. The crack location was kept fixed at mid-line of the tested plate.

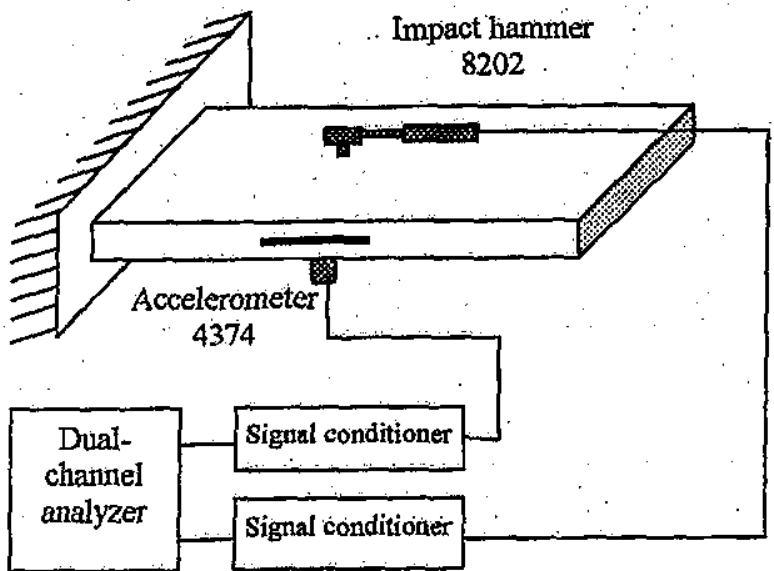

Fig. 3 Configuration of experimental set-up for damage detection

\subsection{Ultrasonic Measurements}

Ultrasonic measurements for internal friction $\left(Q^{-1}\right)$ and phase velocity $(\mathrm{Cp})$ were based on the application of magnatostriction phenomena [23]. Figure (4), shows the basic system used for these measurements while the recorded signal echo is schematically shown in Fig. (5).

The first part of the echo including the cross-over, is the direct return of the transmitted signal, whilst the second part, the decrement, is the exponential retransmission of the energy stored. The number of oscillations to the cross over is a function of the line (wire) cross-section and the properties of resonating material. The parameters shown in this figure are used to calculate, absolutely, the internal friction according to the following equation [23]:

$$
\frac{Q c}{Q M}=\frac{A 0+A \infty}{A 0-A \infty}=X
$$

Where $Q c$ and $Q m$ are coupling and material Qvalues respectively.

$$
\text { and } \frac{\Pi \Pi N}{Q c}=\frac{\operatorname{Ln}[2 /(1-X)]}{1-X}
$$

Internal friction values were calculated with standard variation $( \pm 0.0019)$. The longitudinal resonant modes of vibration of each tested composite specimen were excited by cementing it with the remote end of the delay line (wire $1 \mathrm{~m}$ long and $1 \mathrm{~mm}$ dia. made entirely from nickel) of the system. The corresponding resonance frequencies were detected. For a specimen of length $L(m)$, vibrating at its natural frequency $\mathrm{f}(\mathrm{Hz})$, the phase velocity $\mathrm{C}_{\mathrm{p}}(\mathrm{m} / \mathrm{sec})$ is related to this resonance frequency by [23].

$$
\mathrm{C}_{\mathrm{p}}=2 \mathrm{~L} \mathrm{f} / \mathrm{n}
$$

The most accurate dynamic Young's modulus $\left(\mathrm{E}_{\mathrm{D}}\right)$ usually follows from determining ultrasonic phase velocity $\left(C_{p}\right)$ as using the general relationship [24].

$$
E_{D}=\rho C_{p}^{2} \text {. }
$$
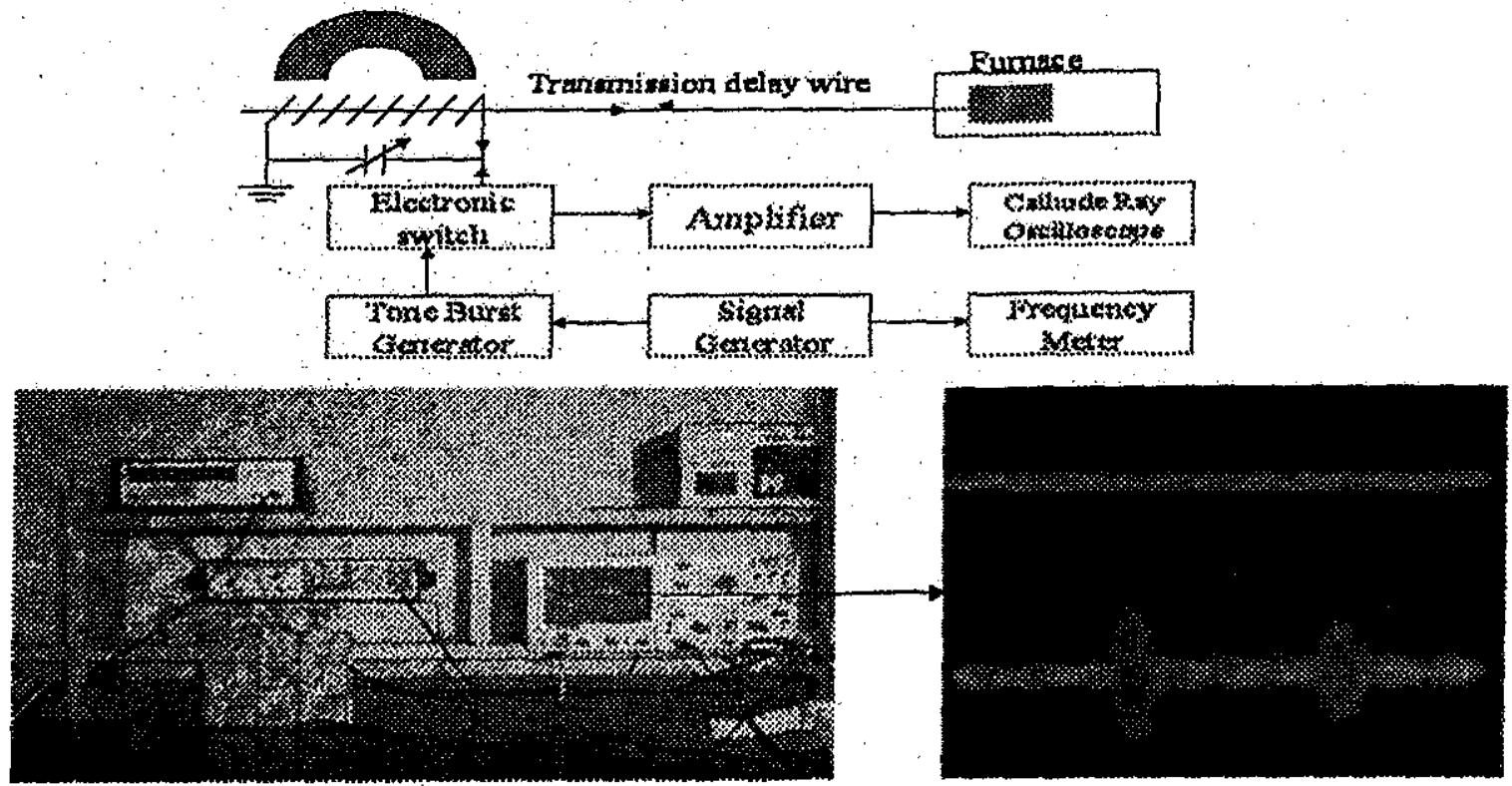

Fig. 4 Set-up of ultrasonic measuring system and the resultant echo 


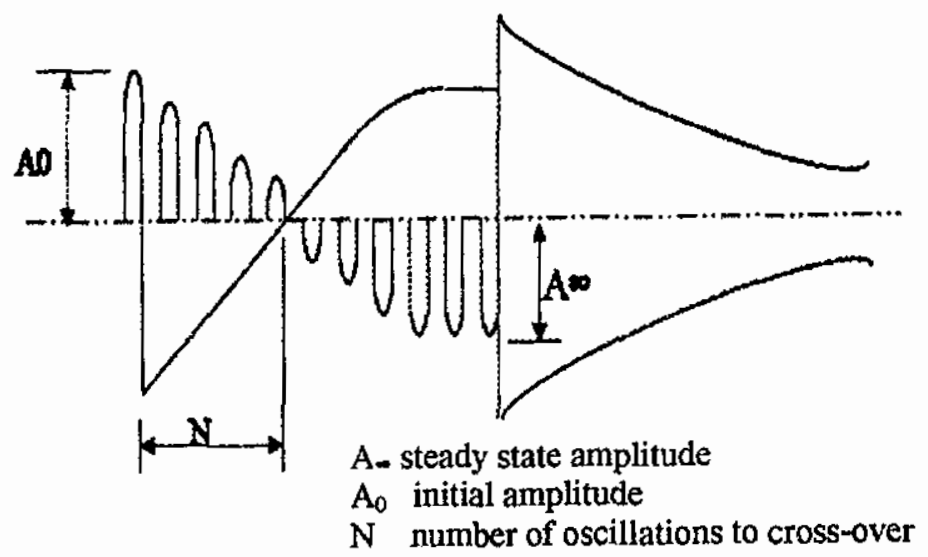

Fig.5 Schematic diagram of the resultant echo-pattern displayed in the magnetostractive delay-line system
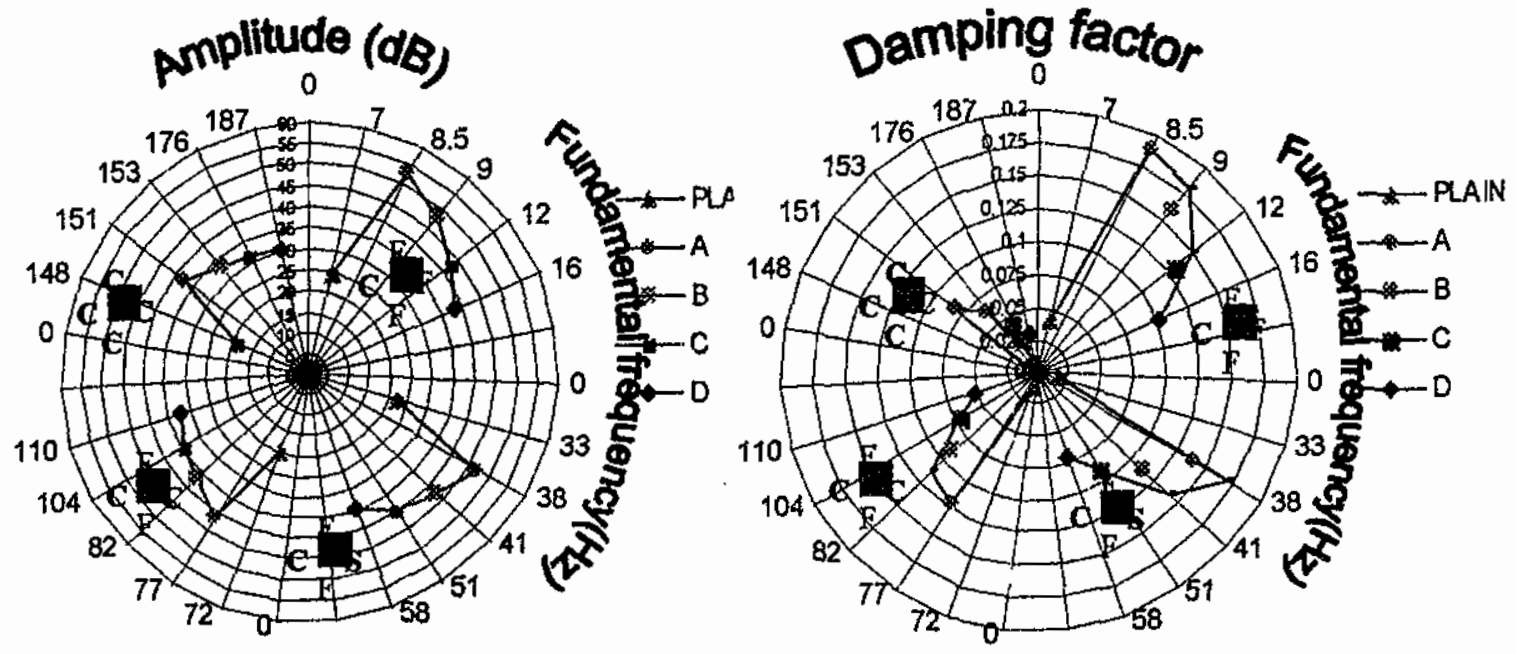

Fig. 5 Variations of fundamental frequency with amplitude a), and with damping factor b), for various boundary conditions and mesh configurations

\section{RESULTS AND DISCUSSION}

The resonant frequencies, mode shapes and damping factors of square ferrocement composite plates have been measured and analyzed for different mesh configurations and boundary fixations. The measured and computed values of the frequencies are given in Table 1. Comparisons between the experimental and numerical results of the frequencies indicate good agreements. Table 2 shows the variation of fundamental frequencies, amplitude and damping factor for different mesh configurations at the same plate thickness. It can be seen that the damping factor of plate $\mathrm{A}$ is relatively high compared with the other. This is due to the maximum dissipated energy at this mesh reinforcement. Also, it can be noticed that the damping factor of plain plate is relatively low compared with the other due to the small stiffness value for this case of bulk material. As expected, the measured frequencies are inversely proportional to damping factor as shown in Fig.5.
In general, the damping factor in composite materials is relatively high relative to bulk materials. It is difficult to control the value by variation of the mass and stiffness. From Fig.5, it can be noticed that minimum values of the damping factor occur in the case of clamped [CCCC] plates with different types of mesh configuration. In all boundary conditions, it is observed that the damping factor is small for mesh type [D] compared with other reinforced type. This explained by the fact that mesh reinforcements are expected to increase the plate stiffness and result in less energy dissipation. In view of the state of fixation, it is observed that the effect of the degree of constraints is dominant on values of natural frequency and damping factor compared with the variation of the open mesh type.

Fig (6) shows mode shape for a few selected cases of tested plates for different boundary conditions. Determination of the natural frequencies and mode shapes of a vibrating structure is an important aspect from the stand point of view of the 
structure dynamic behavior. The natural frequency gives information about resonance avoidance for certain loading conditions. Mode shape, on the other hand, gives indication about the vibration level at each position of the structure. One of the most important parameters from designer's point of view is the location of nodes and antinodes. The nodes ate the positions at which the vibration vanishes, the maximum stresses induced at these nodes. While the antinodes are the positions at which maximum vibration level cccurs.

In Table 3, the natural frequencies and damping ratios for the cracked $D$-plate under cantilever fixation are set out based on the dynamic measurements. A group of natural frequencies can be recognized that represent the dynamic chatacteristics of the noncracked plate; that the natural frequencies in this group decrease proportionally until a critical debonding extend $(\approx 20 \mathrm{~mm})$ is reached. The damping ratio in this group shows an increase, while the natural frequency decreases. Beyond this critical debonding extent, another group of frequencies decreases which represents the dynamic characteristics of the damaged plate. The damping ratios in this group increase noticeably beyond the critical debonding extent

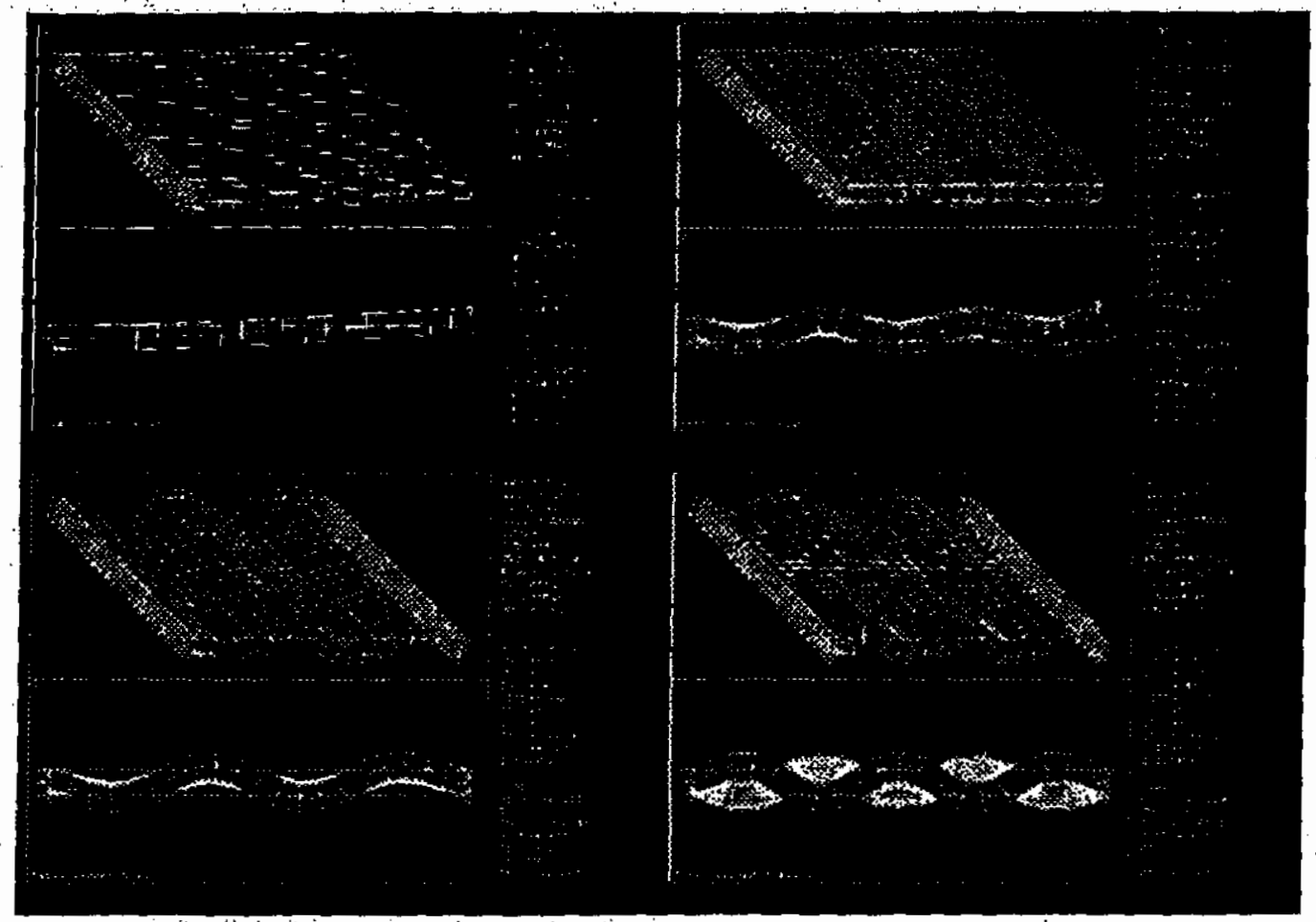

Fig. 6 Mode shapes for few selected cases of tested plates for different boundary conditions

Table (3) Natural frequencles and damping factor for the cracked D-plate under cantilever fixation

\begin{tabular}{|c|c|c|}
\hline Crack length mm & N Frequency, Hz & Damping ratio \\
\hline Intast & 96 & 0.09 \\
\hline 10 & 93 & 0.10 \\
\hline 20 & 83 & 0.14 \\
\hline 30 & 70 & 0.18 \\
\hline 40 & 53 & 0.39 \\
\hline 50 & 29 & 0.56 \\
\hline
\end{tabular}

\subsection{Ultrasonic Rèsults}

The ultrasonic phase velocity propagating in the specimen (Cp), the dynamic elastic modules Ed as well as the internal friction $(\mathrm{Q}-1)$ for the first two echoes are given in Fig. (7). It is clear that the ultrasonic wave propagating in plain specimen is attenuated by various factors mainly voids, lack of homogeneity, cracks etc. This explains the lower Cpvalues for the dummy compared with the composites plates by almost $50 \%$. Such attribution could explain the high (Ed) - values for composite compared with dummy by almost $70 \%$. Regarding internal friction values, Fig. (7) shows that the composite plates have high Q-I values compared with the dummy plates. 
Let us try to offer an explanation for the improved damping for the composite plate based on arguments other than defectology. The composite plates consist of steel mesh sandwiches within more layer and so can be considered as viscoelastic material, i.e. posses both elastic and viscous properties. Thus some of the energy stored in a viscoelastic system is recovered upon removal of the load, and the remainder is dissipated by the material in the form of heat, resistance. So when the composite plate is subjected to ultrasonic energy, the mesh layer begins to slide resulting in a shearing action compared to matrix material. The pattern does more than just bond the mesh to the matrix; it also provides the mechanisms that create the damping effects as these shear strains are converted to heat energy within viscoelastic material. The dependence of Q-1 values on steel mesh configuration is further observed from Fig.(7). From which, plate A has the higher Q-1 values compared with plate D. In ferrocement composites, two kinds of interfaces: strongly bonded interface and weakly bonded interface, can be identified. For a strongly bonded interface (case- D), it is assumed that bonding between metal mesh is strong enough to resist.sliding between matrix and reinforcement. When the interface is weakly bonded, sliding at the interface is more likely to occur. Interfaces between different phases in multicomponent material system (the case of the present work), may offer various possibilities for vibration energy dissipation. Poorly bonded interfaces are generally expected to increase damping through friction or columbic sliding mechanisms.

The data shown in Fig.(7), strongly support the idea that the stiffer materials (high Ed-values) could have a higher internal friction. In this regard, steel mesh configurations (volume fraction of fiber, open mesh area, wire dianeter....) have a specific contribution to keep both stiffness and damping at high levels. However, to quantify the specific weight of these parameters on damping necessitates further experimentation. In our opinion, this step will be of special interest and will open a new important area for ferrocement composite structure in dynamic fields.

\section{CONCLUSION}

The dynamic behavior of ferrocement plates reinforced with various steel mesh configurations was investigated experimentally and numerically under different boundary conditions. The experimental techniques were employed, namely ,hammering excitation for law frequency ranges and ultrasonic attenuation for high frequency ranges( up to $120 \mathrm{kHz}$ ). The following conclusions were arrived at:

1. The dynamic characteristics of FC plates differ considering depending on mesh configurations and boundary conditions. There for FC structures may be tailored for specified modal parameters and nodes positions to satisfy certain operations conditions.

2. The numerical results from FEM indicate good agreement with those obtained from modal analysis .However, it is recommended to use finer mesh for the numerical FEM considering more nodes of vibration.

3. Damping of the investigated composites is relatively higher than those un-reinforced by almost five times. Also, the larger the open mesh area (type D-80\%), the lower was damping capacity compared with type A $(68 \%)$.

4. The positions of the nodes and antinodes are shifted for FC plates compared with the plain ones.

5. Damage identification based on FRF can accurately determine the extent of the damage from natural frequency and damping ratios.

6. In the high frequency range (ultrasonic data), the reinforced plates have higher stiffness and damping compared with the un-reinforced plates. In this regard, steel mesh configurations (volume fraction of fibers, open mesh area, wire diameter,..) have their specific contributions to keep both stiffness and damping at high levels .However, further experimentations one required to quantify the specific weight of those parameters on ultrasonic data.

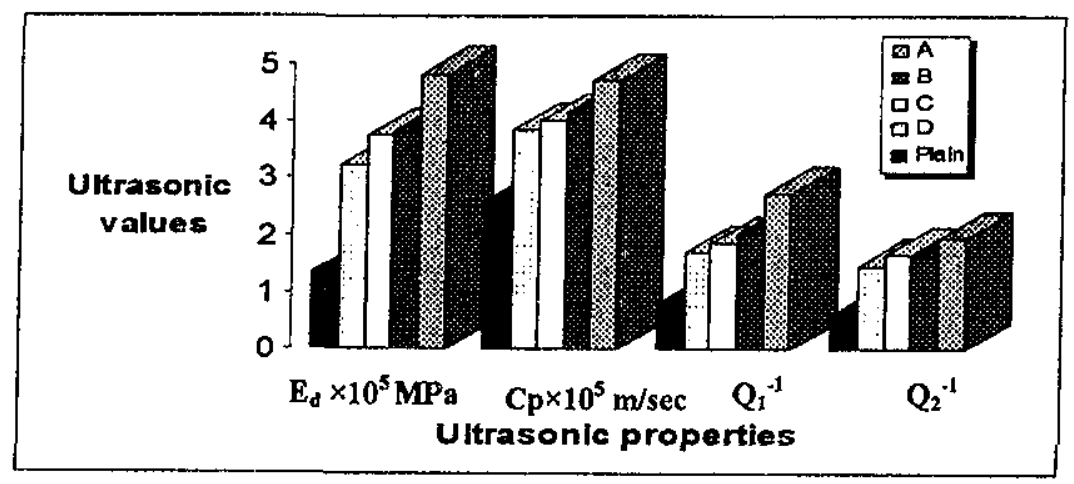

Fig.7 Experimental data from ultrasonic measurements 


\section{REFERENCES}

[i] ACI Committee 549, "State-of-the-Art Report on Ferrocement", ACI 549-R97, in Manual of Concrete Practice, ACI, Detroit, 1997, 26pp.

[2] Shah, S.P and Naaman, A.E., "Crack Control in Ferrocement and Its Comparison with Reinforced Concrete," Journal of Ferrocement, V. 8 , No. 2,1978 , pp. $67-80$.

[3] Arif, P.M., and Kaushik, M. A. "Mechanical Behavior of Ferrocement Composites", J. Mat. in Civ. Eng: V. 14, 2, 2002, pp. 156-163.

[4] Guerra, A.E., Naaman, A.E. and Shah, S.P., "Ferrocement Cylindrical Tanks: Cracking and Leakage Behavior," ACI Joumal, Proceedings, V. 75 , No. 1, Jan, 1978, pp. 22-30.

[5] Nimityongskul, P.; Chen Bor-Shiun and Karasudhi, P., "Impact Resistance of Ferrocement "Boat Hulls," Journal of Ferrocement, V.10, No. 1, 1980, pp. 1-10.

[6] Kadir, M.R.A., Samad, A.A.A., Muda, Z.C., and Abang Abdullah, A.A., "Flexural Behavior of Composite Beams with Ferrocement Permanent Formwork," Journal of Ferrocement, V. 27, No. 3, 1997, pp. 209-214.

[7] ACI Committee 549-1R-88, "Guide for Design Construction, and Repair of Ferrocement" ACI 549-1R-88 and 1R-93, in Manual of Concrete Practice, ACI, Detroit, 1993, 27pp.

[8] Bingham, B.; "Ferro-cement Design, Techniques, and Applications", Comell Maritime Press; Cambridge, Maryland, 1974, 444pp.

[9] Naaman, A., "Ferrocement and Laminated Cementitious Composites", Techno Press 3000, Ann Arbor, Michigan, 2000, 372pp,

[10] Naaman, A.E., and Ai-Shannag, J. "Ferrocement with Fiber Reinforced Plastic Meshes: Preliminary Investigation," Proceedings of the Fifth International Symposium on Ferrocement, Manchester, England, September 1994. P. Nedwell and N.R. Swamy, Editors, E. and FN SPON, London.

[11] Guerrero, P. and Naaman, A. E., "Bending Behavior of Hybrid Ferrocenient Composites Reinforced with PVA Meshes and PVA Fibers," Ferrocement 6 . Lambot Symposium, Proceedings of Sixth International Symposium on Ferrocement, "Naman, A.E., Editor, University of Michigan, Jüne 1998.

[12] Hammoud, Hassen "Study of Ferrocement Bolted Connection for Structural Applications" $\mathrm{Ph} . \mathrm{D}$-Thesis, University of Michigan, 1993.

[13] Naaman, A.E., and Chandrangsu, K., "Bending Behavior of Laminated Cementitious Composites Reinforced with FRP Meshes," High
Performance Fiber Reinforced Concrete Thin Sheet Products, Edited by A. Peled, S.P. Shan and N. Banthia, ACI SP-190, American Concrete Institute, Farmington Hills, 2000, pp. 97-116.

[14] Lopez, M. and Naaman, A. E., "Study of Shear Joints in Fiber Reinforced Plastic (FRP) Ferrocement Bolted Connections," Ferrocement 6 - Lambot Symposium, Proceedings of Sixth International Symposium on Ferrocement, Naaman, A.E., Editor, University of Michigan, June 1998.

[15] Salawn, W. "Bridge Assessment Using ForcedVibration Testing', Journal of Structural Engineering,Vol.121,No.2,Feb.,1995,pp.161172.

[16] Koh B. and Ray L., "Localization of Damage in Smart Structures Through Sensitivity Enhancing Feedback .Control", Mechanical System and Signal Processing 1566, 2003, pp.1-19.

[17] Richardson M., "Determination of Modal Sensitivity Function for Location of Structural Faults", The 17th International Modal Analysis Conference, Kissimmee, FL, Feb.,1999.

[18] Zienkiewicz, O.C. and Taylor, R. L., "Finite Element Method" 4th edn. McGraw-Hill, New York 1989.

[19] Krawczuk, M. " A Rectangular Plate Finite Element with an Open Crack" J. of Computers and Structures Vol. 46, No.3, 1993, pp 487-493.

[20] Epstein, M. and Huttelmaier, H.P., "A Finite Element Formulation for Multilayered and Thick Plates" J. of Composite Structure, Vol. 25, 1993 , pp 645-650.

[21] Hamada, A., El-Taweel T. A., Elsissy M. A., "On the Modelling of the Dynamic Behavour for Ferrocement Composite Plates", Fourth Assiut University Int. Conf. on Mech. Eng. Advanced Tech. For Indus. Prod., December 12-14, 2006, pp 546-556.

[22] Khafagy A. H., "Acoutical and Mechanical Investigation on Metallic and Dielectric Solid Media", Ph. D Thesis, university of London, 1985.

[23] Nesvijski, E. G., "Some Aspects of Ultrasonic Testing of Composites", Composite Structures, V 48, 2000, pp 151-155.

[24] Moreno E., Castillo, M., "Ultrasonic NDT in Ferrocement", Ultrasonic Symposium, IEEE, Atlainta, GA, USA, 2001, pp. 777-780.

[25] V. Rajendran, A. V. Gayathri Devi, M.Azooz, F. H. El-Batal, "Physicochemical studies of phosphate based $\mathrm{P} 2 \mathrm{O}$ - $\mathrm{Na2O}-\mathrm{CaO}-\mathrm{TiO} 2$ glasses for biomedical applications", journal of NonCrystalline Solidis Vol. 353, 2007, pp 77-84. 